\title{
How to Research People's First Impressions of Websites? Eye-Tracking as a Usability Inspection Method and Online Focus Group Research
}

\author{
Csilla Herendy \\ University of Pécs, Budapest, Hungary
}

\begin{abstract}
The visual surface of the Hungarian governmental portal - magyarorszag.hu - was inspected in 2007 with two different inspection methods: Eye tacking research and Online focus group research. Both methods help to understand and to chart not only the usability of different websites but also the affective impressions associated with the websites. In this study, an Experimental and a Control-group were tested to assess the usability of the site and the emotional reactions to it. The results reveal that the Hungarian government website is too complicated, dull and difficult to apprehend at a glance.
\end{abstract}

Keywords: Eye-tracking; online focus-group; website usability.

\section{Introduction}

In this study, the Hungarian governmental portal, called magyarorszag.hu (in English: hungary.hu) was researched with the use of two different methods, eye tracking research and online focus-groups. The aims of this study were to investigate and assess the usability of the main page of the site and to survey the first impressions and the emotional reactions to the website. The ease (or difficulty) of finding different pieces of information on the site was tested, and users' evaluations of the site as simple or too complicated were investigated. The survey focused on other question as well: the impressions users had of the civil servants who worked at the portal and of the Hungarian administrative sector, after using the site and experiencing the user interface and the visual surface.

The possible uses of different testing methods for websites are highlighted by various studies, such as Usability Inspection Methods [1], F-Shaped Pattern for Reading Web Content [2]. One of the most promising modern tools is eye tracking, as discussed by, for instance, Nielsen [2], Duchowski [3]. These studies concentrate of the eye-movements of the users: how they look at web pages, what they read, what they don't read, what they tend to notice or never see, etc.

Using the eye tracking method, the aim of this survey was to reveal how users find certain information on the site and whether the site meets their general needs and expectations.

In addition to the eye tracking method, online focus groups were used as well. The aim of applying the online focus group method was to obtain information about emotional reactions to the site in an effort to understand why the users liked or disliked 
the site, why they judged the site as difficult or simple, how they felt about the people working behind the site (civil servants).

The online focus group completed a range of qualitative and quantitative surveys: semantic differential scale, interviews, collage-making and incomplete sentences test. The users were interviewed about the page, about the results of the eye tracking study, and they were asked to compare the Hungarian portal with the governmental portals of other countries, including those of the USA, Japan, South-Korea and Germany. The countries were selected based on a survey conducted by Waseda University Institute [4].

The present survey could help to understand how users feel about governmental websites, especially about the Hungarian portal. The eye tracking method helps to understand which piece of information is positioned optimally and which is not; the online focus group helps to assess users' opinions. In order to identify possible shifts in attitudes after using the site for practical purposes, our participants were divided into two groups. One group (the experimental group) took part in the eye tracking study, where the users were asked to find some information and some links on the website, while the other group (the Control group) was only exposed to the website for the purposes of focus group tasks.

\section{Method}

In this study, the Hungarian governmental portal, called magyarorszag.hu (in English: hungary.hu) was researched with the use of two different methods, eye tracking research and online focus groups. The eye-tracking method was used to assess the usability of the website, by measuring speed and tracking eye movement in solving different tasks on print screens from the website.

The online focus group was used to complement and help interpret the results obtained in the quantitative research on the one hand, and to introduce an additional variable for comparing the attitudes of users solving tasks on the site and users viewing the site without any tasks. I was also interested in exploring the general attitudes of users in both groups.

I chose to use online focus groups instead of seating participants together because it makes more accurate data readily available.

First I write about the eye tracking research.

For the research, the eye tracker of the Faculty of arts of the Hungarian Eötvös Loránd University was used. The eye tracker, called "Remote Eye tracking System" was developed by LC Technologies.

This appliance allows a very accurate analysis of the behavior of the users. The appliance is non-obtrusive, which means that there is no need to place it on the head of the user. Eye tracking is the process of measuring either the point of gaze ("where we are looking") or the motion of the pupil relative to the head. An eye tracker is a device for measuring eye positions and eye movements. Eye trackers are used in research on visual surfaces, in psychology, in website-usability or in product design. There are a number of methods for measuring eye movements.

This video-based eye tracker works on the following operating principle: two cameras, placed on a monitor, focus on both eyes and record their movement as the viewer looks at some kind of stimulus. The "Remote Eye tracking System" uses the 
contrast between the iris and the pupil. The system uses infrared and near-infrared, non-collimated light to create data from the corneal reflection. The vector of these two features can be used to compute gaze intersection with a surface after a simple calibration for an individual.

Using the data, the system makes different overview maps about the eye-movements. Using this map, it is possible to establish clearly how the users watch the visual surface, which part of the surface is more and which is less interesting for the users [5].

The "Scanpath analysis" shows the sequence of the fixations and their exact duration. About saccades and fixations: While drawing a visual information, the eyemovements are mostly not smooth and regular. On the contrary: while watching a visual surface, there are different eye-movements of interest for the present survey. One of them is the saccades - rapid eye movements used in repositioning the fovea to a new location in the visual environment -, the other one is the fixations - eye movements that stabilize the retina over a stationary object of interest [3]. This eye movement is recordable during the eye tracking surveys.

The "Attention level" and the "Hotspot" maps show the length of the fixations, the degree of visual attention. These maps show in a very clear graphic form how the users (part of the experimental group) watched the visual surface. It can be particularly interesting when the users watch websites.

\section{Participants}

Two groups took part in the research (the Experimental group, 6 users, participating in the eye-tracking research and the Control group, not participating in it).

The average age of the participants was almost identical in both groups (29-30 years). Participants included 6 women and 7 men, 5 from rural areas of Hungary and 8 from Budapest. Two of the subjects had secondary education, 11 had higher education degrees. They had a wide range of interests (information technologies, communication, agility, ceramics, etc.), three of the subjects had young children, and three of them were PhD students.

Table 1. Participants' data

\begin{tabular}{llll}
\hline & Number & Average age & Age range \\
\hline Experimental Group & 6 & 30,2 & $21-43$ \\
Control Group & 7 & 29,9 & $26-40$ \\
\hline
\end{tabular}

\section{Eye Tracking and Online Focus Group Research on the Hungarian Governmental Portal}

\subsection{Eye Tracking Research}

The research took place at the Eye tracking Laboratory of the Faculty of Arts of the Hungarian Eötvös Loránd University. The participants arrived after each other. They sat down in front of the screen and were told about the essence of the eye tracking 
technology and the process of the research. The leader of the research was sitting behind the participants.

The research was conducted in 3 phases:

First, the users were shown unrelated pictures on a computer screen before the test phase of the experiment (family pictures, landscapes, and different websites). This phase was included in order to train the users not to try to influence their gaze.

In the next phase, the users were shown a Print Screen of the test site on the computer screen (only the first page). The Print Screen was made May $17^{\text {th }} 2007$. (See Fig 1.)

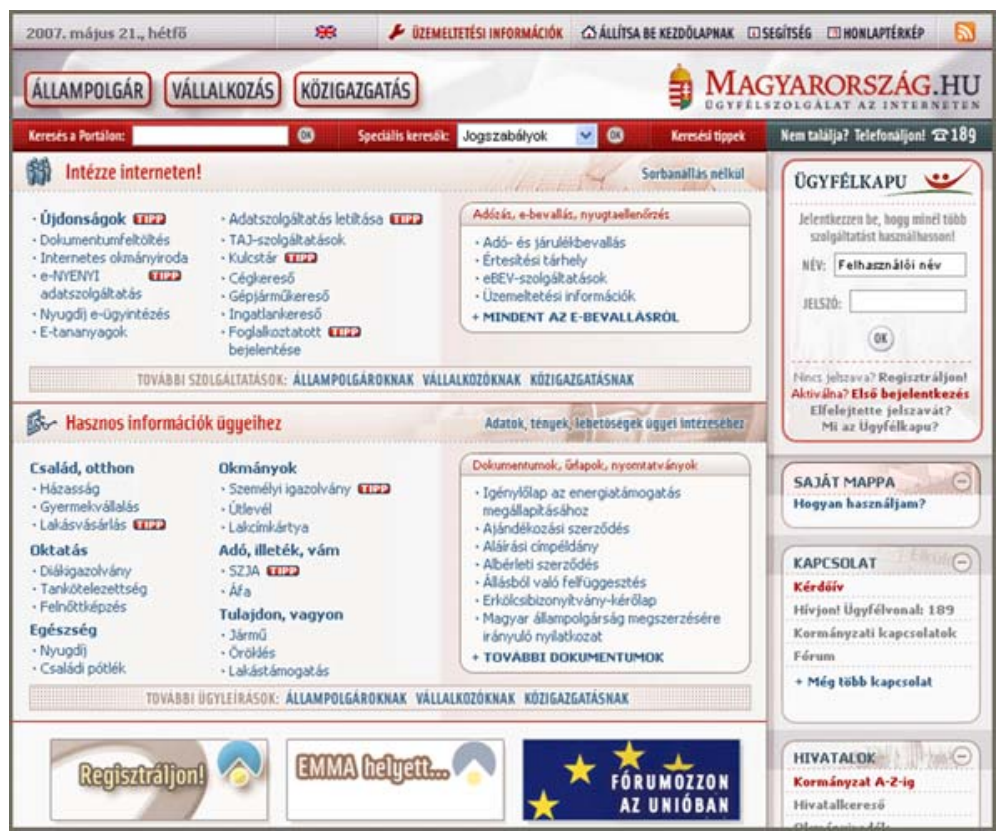

Fig. 1. Print Screen of the site: Magyarorszag.hu

In the third and longest phase of the survey the users were asked to find some information and some links on the site.

These were of two types: basic links (sending an e-mail message, map, search box, back to the main page link) and popular functions (according to official site statistics): "tax and contribution returns", "Home, family" and "Company search" and other specific menus: "Can't find it? Call us!", "Search tips", "The most frequent search topics", "Call us on 198" and the Hungarian national Coat of Arms.

The participants saw the pictures one by one. They walked through the pictures at their own pace, stepping on the next by using the "space" key.

\subsection{Results of the Eye Tracking Research}

The eye tracking research revealed that the participants found certain functions very easily while others were found only after a long search. 
The easy links were: "Date", "the Hungarian national Coat of Arms, "Search tips", and "Ügyfélkapu"; the search for "The most frequent search topics", the "Home, family" and the "Company search" took a long time.

The exact search duration was tracked and listed by the program of the Eye tracker (See Table 2.)

Table 2. Scanpath Duration (ms) - The time of finding the links and functions

\begin{tabular}{|c|c|c|c|}
\hline No. & Task & Mean & Median \\
\hline 1 & Please view the magyarorszag.hu site! & 13375,67 & 13803,00 \\
\hline 2 & Please find the "Search at the site" link on the Print Screen! & 9539,33 & 7113,50 \\
\hline 3 & $\begin{array}{l}\text { Please find the "Hungarian national Coat of Arms" link on } \\
\text { the Print Screen! }\end{array}$ & 1959,33 & 1198,50 \\
\hline 4 & Please find the "Map" link on the Print Screen! & 6459,00 & 4308,50 \\
\hline 5 & $\begin{array}{l}\text { Please find the "Tax and contribution return" link on the } \\
\text { Print Screen! }\end{array}$ & 14412,83 & 8103,00 \\
\hline 6 & Please find the "Home, family" link on the Print Screen! & 21033,50 & 3738,00 \\
\hline 7 & Please find the "Set as homepage" link on the Print Screen! & 12882,50 & 4008,00 \\
\hline 8 & Where is the date? (" $31^{\text {st }}$ May, 2007. Monday") & 1718,33 & 1846,50 \\
\hline 9 & $\begin{array}{l}\text { Please find the " Can't find it? Call us!" link on the Print } \\
\text { Screen! }\end{array}$ & 4478,50 & 1586,50 \\
\hline 10 & Please find the "Search tips" link on the Print Screen! & 2310,67 & 2088,00 \\
\hline 11 & $\begin{array}{l}\text { Please find "The most frequent search topics" link on the } \\
\text { Print Screen! }\end{array}$ & 19310,33 & 12677,00 \\
\hline 12 & Please find the " Call us on 198 " box on the Print Screen! & 9657,17 & 8262,50 \\
\hline 13 & Where would you click to go back to the main page? & 11100,33 & 12648,00 \\
\hline 14 & Where would you look for the "Write e-mail" possibility? & 4647,00 & 4499,00 \\
\hline 15 & Where is the "Ügyfélkapu" box? & 3374,83 & 1195,50 \\
\hline 15 & Please find "Company search" box on the Print Screen! & 29601,50 & 26907,00 \\
\hline
\end{tabular}

\subsection{Online Focus Group Research}

The Online focus group was organised at the laboratory of the Faculty of Arts of the Hungarian Eötvös Loránd University.

The research leader, the moderator and an IT expert who were responsible for the program were sitting at the laboratory, the participants were at home and they used their own computer. The participants got a link and downloaded the necessary program for taking part in the online focus group research.

Two focus groups were organised: an Experimental group and a Control group. The two focus groups took place on the same day, in the afternoon, about 6 and 7 o'clock.

\subsubsection{Warm-Up Phase}

The focus group research started with "warming-up": the moderator asked the participants (of both groups) about their internet-use, and whether they use administrative websites or not. The participants said they often use the internet for orientation and for finding information. They also said they know several public administration sites. 
The moderator asked the participants to visualize (recall) the website magyarorszag.hu. The participants of the Experimental group remembered pale colours, white, red and bourdon (ruby). Then they were asked to talk about their impressions of the site; the answers included "boring", "monotonous", "non-functional", "bureaucratic".

At the question "What do the colours suggest?", the participants answered "bland", "boring", "unimaginative", "boring part of a boring system", "there weren't too many colours on it, what I remember is only a white background and some small, grey characters".

They described the structure of the site ("simple or complicated?") as follows: "tangled", "dense", "diffuse". Then the moderator showed a Print Screen about the site and asked the participants for their opinion. They said "so, then I remembered well”, "illogical composition", "grey", "it's not too imaginative”, "it doesn't look like a professional site, I have problems with it's distribution, the general appearance is more or less OK".

When the Print Screen was shown to the Control group, they described their impressions as follows: "cluttered", "dense", "too much text", "it's simple but a bit confusing, I see suddenly too much text", "it's a little glum", "it's like public administration, greyish, like nothing, cold".

About the structure of the site: "it looks difficult and muddled", "there should be a bit more contrast on it", "it should be a bit more airy', "it looks too difficult at the first sight but if I look it isn't", "it is too much, muddled".

At the warm-up, the participants of the groups were critical about the site's colours and structure. The answers of the groups did not differ too much. Their opinions of the group (and the differences between their opinions) were specified by the semantic differential scale.

\subsubsection{Semantic Differential}

The semantic differential method is a type of rating scale [6], for measuring the emotional charge of concepts, ideas, objects and events. The participants were asked to indicate their position on a 1 to 6 scale between two contrasting words (e.g. cold warm, friendly - stuffy, strong - weak, formal - casual).

Both groups' participants evaluated the magyarorszag.hu site at the Semantic Differential. In the whole research, this method showed the biggest difference between the two groups' opinions. The participants of the Experimental group who tried to find different links at the site were much more critical than the participants of the Control group.

The semantic differential is a scale between two contrasting terms. The participants were asked to choose their position on the scale. The biggest divergence between the two groups' opinions was found for:

- How customer-friendly is the site?

- Is the site old-fashioned or innovative?

- I like it / I don't like it

- Is the site formal or casual?

- Is the site complicated or transparent?

- Is the site trustworthy or untrustworthy?

- Is the site cold or friendly? 
In both groups the "winning" attributes were: "difficult", "monotonous", "boring". The participants also found the site bureaucratic and too formal, more gloomy than cheerful, more old-fashioned than modern, slow rather than fast, more boring than entertaining, and more monotonous than colourful. Both groups awarded the site the same points for conservative and liberal (1-1), and for superficial and accurate (0 - 0 point), which means that these parameters are not relevant for the site.

On the whole, we can see that the participants of the Experimental group - those who took part in the eye tracking survey - rated the site more negatively on almost all scales than did the participants of the Control group.

These differences point to the fact that the experimental group's opinion is not based on stereotypes but on the difficulties they experienced during the eye-tracking research.

\subsubsection{Incomplete Sentences}

In the incomplete sentences exercise the participants get unfinished statements and are asked to complete the sentences. An important advantage of this technique is that it may yield spontaneous answers [7].

In this exercise both groups got sentences about the site - about its appearance, about the easiness of orientation, and about the virtual civil servants working "behind" the site.

In this part of the survey, the participants of the Experimental group were again more critical than the participants of the Control group: they didn't use a single positive attribute.

The appearance of the site was described in both groups as "boring", "monotonous", "dreary". The participants of the Control group characterized the site mostly as "boring", "cold", and as one that "needs development"; a single refreshing exception was: "pleasant". The general design and the atmosphere of the site were described as "depressed", "unimaginative", and "too grey".

The Experimental group pictured the "workers of the site" (the civil servants) as "unimaginative", "bureaucrats", "helpful, reacting quickly to questions", "they can't use the site either", "not really thoughtful". The Control group expressed the opinion that the workers of the site are "normal people", "drinking coffee", "no good people", "insipid and have a lot of time", "wearing grey, with a red ribbon only at Christmas".

About orientation on the site ("It is....... to find your way on the site magyarorszag.hu") both groups had a rather bad opinion, with the Experimental group being more explicitly negative about it. Both groups found that it is hard to find one's way on the site, the site is not effective enough. Some participants thought that there is too much information on the main page and they are not optimally placed.

As to whether the site reflects the Hungarian public administration, most of the participants were of the opinion that it does perfectly. Only a few participants thought otherwise.

About the general impression of the site, the Experimental group was again more critical, which allows us to conclude that their answers are not based on stereotypes. Their general impression of the site was that it is "too difficult", "not good", "more constructive remarks included", "you can use it, but it would be nice if they would do something for better usability" and "less would be more". The members of the Control group were somewhat more tolerant: "not too comfortable", "just acceptable", "dense, hard to get an overview", "world wide waiting?". 
It is important to note here that auto-stereotypes may be at work at certain points of the survey ("if something is Hungarian it could only be bad"), therefore it would make sense to control the findings in the future with a bigger survey, containing a blind test with participants who have never seen and used the site, or show the site as the governmental portal of a different country (for example with English, Japanese or German texts).

\subsubsection{Collage-Making}

Collage making is a rather sophisticated but time-consuming method for assessing emotional attitudes [7].

The most interesting part of the survey was probably the collage-making.

The moderator showed the participants previously hand-picked pictures: various types of cars, office workers of different ages and characters; landscapes, office buildings (old-fashioned as well as ultramodern), offices, queues of people, animals, and cities. He then asked the participants to choose one picture per category which they think represents the general atmosphere of the page magyarorszag.hu. Each participant chose one picture from the nine categories, and placed it into a $3 \times 3$ matrix.

In the choice of the pictures there was a clear and interesting difference between the two groups. A few examples: most of the participants of the Experimental group chose the snail from the pictures about animals, while most of the participants of the Control group chose the rabbit, although the difference wasn't too big. From the pictures about offices, most of the participants of the Control group chose a modern office (with Arne Jacobsen's chair in the foreground), while most of the participants of the Experimental group chose a photo about a very old-fashioned office with mountains of paper, old monitors and printers.

There were differences between the pictures of queues: most of the participants of the Control group chose a picture of a man standing in front of a number-dispensing machine. Nobody chose this picture from the Experimental group; they mostly picked the picture showing a long queue.

Since the number of participants in the groups was very low, the differences between the numbers of the chosen pictures are also low. However, even in a small pilot group like this, there are some differences in the attitudes and opinions of the Experimental and the Control group.

The collage-making exercise made a very important feature of the online method apparent: the pictures which were carefully hand-picked beforehand were later easily comparable. Moreover, the time needed for making the collages in this way is very short, whereas in an on-site focus group the participants usually need about half an hour for the same activity.

\section{Discussion}

The aim of the research, organised in May 2007, was to investigate and assess the usability of the main page of the Hungarian governmental portal magyarorszag.hu and to do a survey about the emotional reactions to the website.

A mixed methodology called triangulation was used for data analysis. 
Although the number of the groups (Experimental and Control groups) was relatively low (6 and 7 participants respectively), we can conclude from the results that the visual surface of the main page of the site is complicated, not transparent enough, some of the links are hidden and hard to find. This was confirmed by the Eye tracking research and by the feedbacks from the participants of the online focus group as well.

The eye tracking research also showed that finding some links on the Print Screen of magyarorszag.hu was considerably difficult for the participants. The reasons were the overload of information, the greyish colour of the site, and the way the links are placed on the site.

In addition, the members of the Experimental Group (the participants of which took part in the eye tracking research) were more critical about the magyarorszag.hu site than the members of Control Group.

\subsection{The Eye Tracking Research}

In the eye tracking research, the participants were asked to find various pieces of information on the Print Screen of the site. They found some of the links very easily (quickly), but in the case of some links they needed 25-30 seconds to find them (see Table 2.)

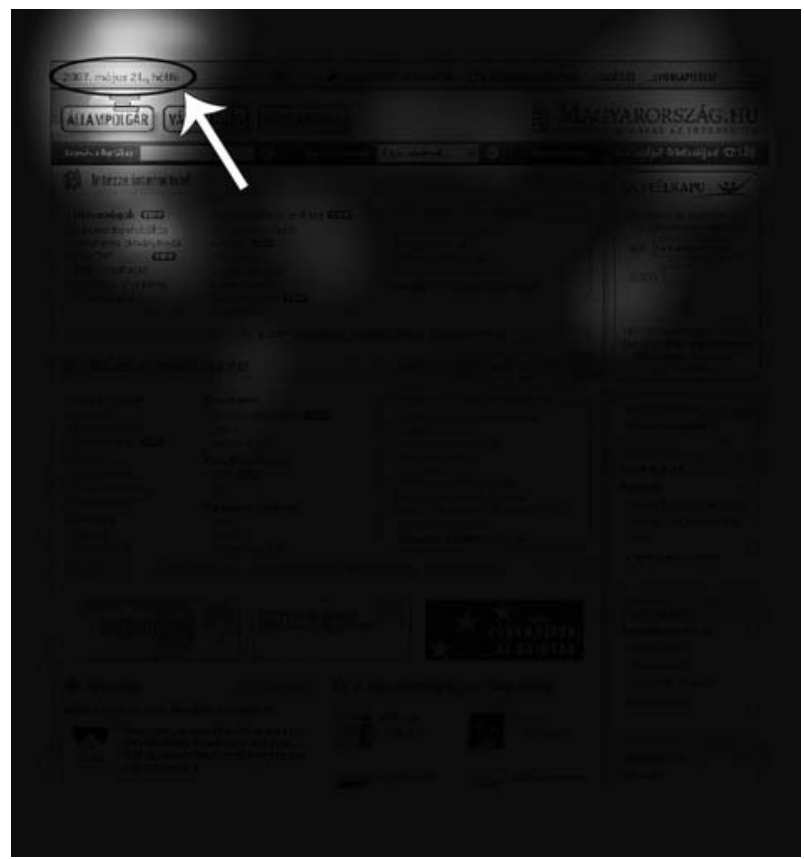

Fig. 2. Attention level map of finding "Date" 
The reason for this can be that some of the links are placed on a relatively obvious place, well-known for site-users. For example, the link called "Ügyfélkapu" or the Date was found easily because it is put on a visible, bigger place. The links "Family, home" and "Company search" were placed between the text-links, hidden for the participants, instead of on the usual place, to the right of the header or under the header.

The searching and finding of the information about „Data” and the link “Company search" are shown on the Fig 2-5. As one can see on the Attention-level maps, the whole surface is black, but the participant's eye-movements are shown in white. (The non-black part of a visual surface shows the level of the visual interest.) That is, the links which are easy to find are shown by some clear, bright spots (see Fig 2.), while the links which are difficult to find are shown by bigger, lighter surfaces (see Fig 3.)

The way the participants found these links is shown in the two Figures about Scanpath analysis (see Fig 4-5). The Scanpath analysis pictures show the eye-movements fixations and saccades - clearly. The fixations are shown with circles of different sizes (the size depends on the time of the fixation), the saccades are shown with lines.

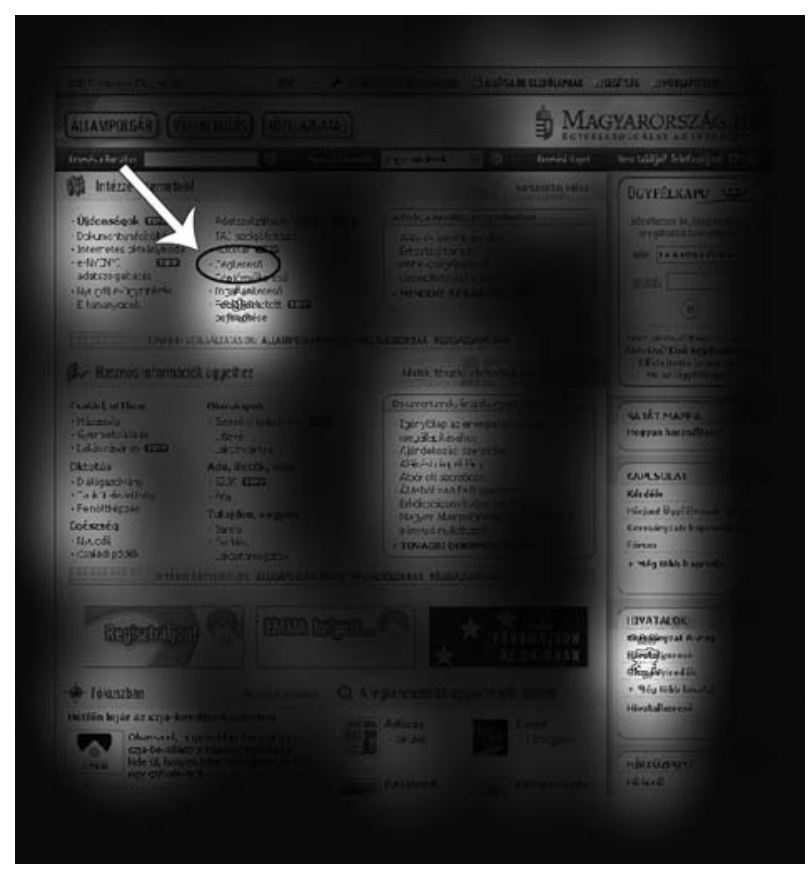

Fig. 3. Attention level map of finding "Company search"

Fig 4 shows how easily the participant found the "Date" link, while Fig 5 shows the difficulty of finding the "Company search" (see the high number of saccades and fixations). The eye tracking research was very useful: although the research was conducted with only 6 participants, the results showed very clearly which links were easy to find, which ones are well placed and which ones are hidden among too much information and in the "wrong" place (not usual on online surfaces). 


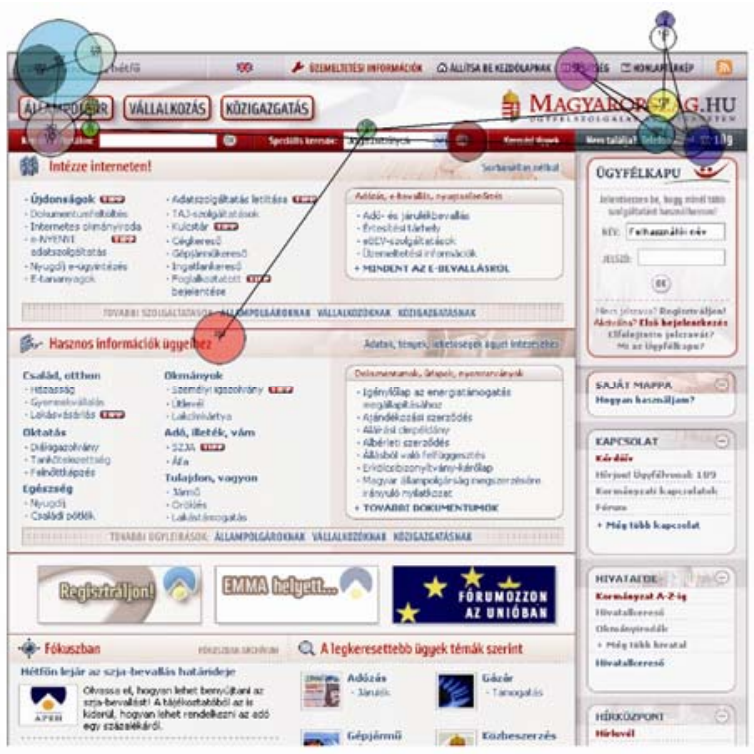

Fig 4. Scanpath analysis map of the finding "Date"

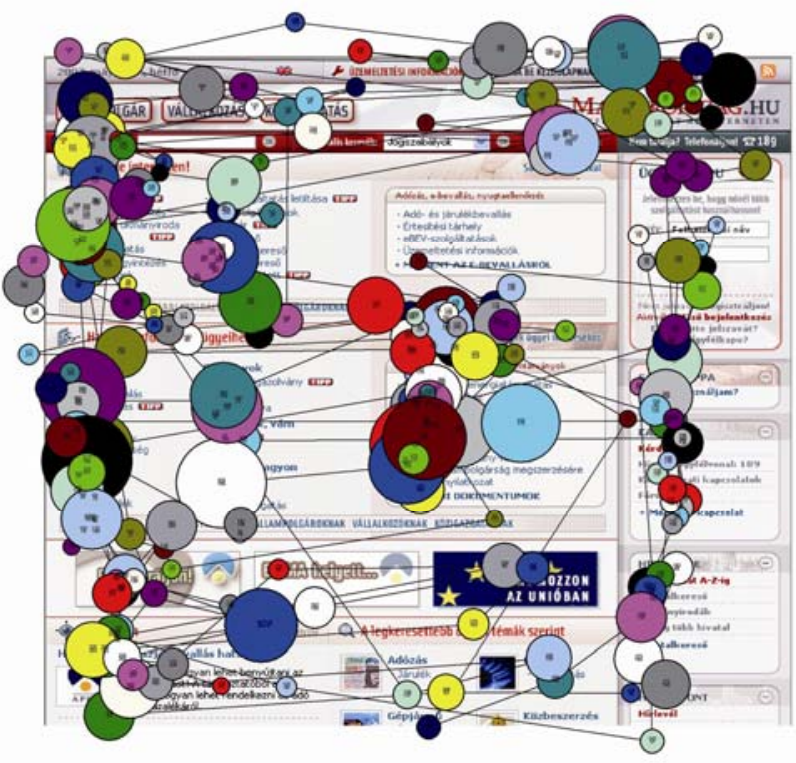

Fig 5. Scanpath analysis map of the finding "Company search" 
Generally speaking, it was easy for the participants to find the links that are placed in the same way as it is usual on online surfaces. Based on the eye tracking research we can say the participants get sometimes totally lost and confused while searching for some links on the site.

This result is all the more interesting since the participants are young and wellpracticed internet-users. One wonders, then, how the less experienced internet-users manage to find the links they need.

\subsection{The Online Focus Group}

The most interesting parts of the online focus group were the semantic differential and the incomplete sentences surveys. Both methods showed the attitudes and opinions of the participants very sensitively.

Both the Experimental and the Control groups had basically negative opinion about the site, though the opinion of the Experimental group members was more negative. The reason for the different opinions is probably the negative experience from the eye-tracking research (the members experienced how hard it was is to find some links on the site).

\subsection{Semantic Differential}

The participants who experienced the difficulty or the easiness of finding the links rated the site less positively. One wonders what would happen if the participants would find every link easily and quickly - would they rate the site more positively than the participants of the Control group? Probably yes. And what if the opinion change of the Experimental group is due to the use of the eye tracker and not to the difficulties of finding the links?

The participants also rated the governmental portals of the countries mentioned before (Germany, United States of America, Japan, and South Korea) on the semantic differential scale. Both groups rated them most positively; they found the sites customer-friendly, simple and trustworthy, non-bureaucratic, friendly, casual, entertaining, cheerful, innovative and liberal, transparent and colourful. The results of the governmental portal of South Korea were almost the opposite of those of the Hungarian portal.

\subsection{Incomplete Sentences}

The incomplete sentences survey also very sensitively showed the differences of opinions between the two groups.

An interesting idea emerged during the research, namely that the magyarorszag.hu site is some kind of picture of the Hungarian public administration: the participants were of the opinion that the site perfectly reflects the Hungarian public administration, since both the site and reality are grey and heavy. The members also thought that the site doesn't show up-to-date online trends.

I would like to stress that the members of both groups had astonishingly similar opinions about the organisation "behind" the site (the site, obviously, has no employees or officials). 


\section{Conclusion}

The visual surface of the Hungarian governmental portal magyarorszag.hu was examined in 2007 with two different inspection methods: eye-tacking research and online focus group research. The use of these two methods enabled us to understand and to chart the usability of the magyarorszag.hu site as well as the affective impressions associated with the websites on the one hand, and to extract the basic attitudes and the first impressions of the users of the site on the other hand.

The survey showed that the magyarorszag.hu site is poorly usable; the members found it too complicated and grey, dull and difficult to apprehend at a glance and the site is a kind of a reflection of the Hungarian public administration.

If this survey is to be continued it would be worthwhile to ask the participants what they exactly think about the question whether the bad orientation, the information overload, the difficult, non-transparent site and the greyish style reflect the Hungarian public administration. Another possible line of research could raise the question of the obtrusiveness of the eye-tracker as a measurement tool in an online study (that is, actually doing the tasks using a mouse, rather than a print screen) comparing the efficiency and performance of users of the site with and without the eye tracker ${ }^{1}$.

An online study using real interaction on the site could yield more sophisticated, realistic and clear results on the same issues.

The survey could also serve as precedent for a bigger, representative survey which could filter out the auto-stereotypes and could help to develop the site into a usable, ergonomic portal.

\section{Acknowledgments}

The author would like to thank for István Síklaki for his continuous assistance and suggestions without which this paper would never have been written.

An earlier version of this paper was presented at Párkány, Slovakia, to the students and teachers of the Communication PhD Program of the University of Pécs. The author is grateful for the audience's suggestions and critical remarks.

The eye tracking survey was made at the Laboratory of the Faculty of Arts of the Eötvös Loránd University. The online focus group was made at the virtual studio of Meroving Ltd., with software, called IQON.

The author's participation and presentation at the IFIP I3E 2009 was supported by the NTP TARIPAR3 Project granted by the Hungarian National Office for Research and Technology, via the E-Government Foundation and Research Team.

\section{References}

1. Nielsen, J., Mack, R.L.: Usability Inspection Methods. Morgan Kaufmann Publishers Inc., San Francisco (1995)

2. Nielsen, J.: F-Shaped Pattern For Reading Web Content, et al (2006), http://www.useit.com/alertbox/reading_pattern.html

\footnotetext{
${ }^{1}$ Thanks to the anonymus rewiever and my professor, Tamás Rudas for this suggestion.
} 
3. Duchowski, A.T.: Eye Tracking Methodology, Theory and practice, pp. 51-52. Springer, London (2007)

4. Waseda University Institute of e-Government, Japan: 2006 World e-Government Ranking by Waseda University Institute of e-Government, Japan, et al (2006), http: / / www.digitaldivide.net/news / view.php?HeadlineID=955

5. Bodor, P., Illés, A., Síklaki, I.: Eye tracking, Theoretical background, et al (manuscript, 2007)

6. Osgood, C.E., Suci, G.J., Tannenbaum, P.H.: The Measurement of Meaning. Urbana University of Illinois Press (1957)

7. Síklaki, I.: Vélemények mélyén. A fókuszcsoport módszer, a kvalitatív közvéleménykutatás alapmódszere, pp. 82-101. Kossuth Kiadó, Budapest (2006) 